\title{
Alat Pembasmi Hama Tanaman Padi Otomatis Berbasis Mikrokontroler Menggunakan Tegangan Kejut Listrik
}

\author{
Devinta Ayu Siregar ${ }^{1}$, Hambali ${ }^{2}$ \\ 1,2 Universitas Negeri Padang \\ Jl. Prof Dr. Hamka Air Tawar, Padang 25131, Indonesia \\ devi.ayu3110@gmail.com ${ }^{1}$, hambali.rsyd@gmail.com $^{2}$
}

\begin{abstract}
In general, the eradication of rice pests is carried out by spraying pesticides. This will cause contamination of soil and rice plants. This study aims to make an automatic pest control device that is environmentally friendly without using pesticides. This research also made a device safety system with buzzer sound notification and short message on android. The method of implementation is carried out in order to successfully make an automatic rice plant pest control device using electric shocks starting from hardware design then collecting data and conducting research by testing the tools in the fields to see the effectiveness of the tools. In this design, the Atmega 328 Arduino UNO microcontroller is used as a system control center, the LDR sensor is used as a substitute for a DC light switch at night to make pests approach according to their characteristics that are attracted to light, then the electric shock voltage will activate every 1 minute to sting pests attached to the wire mesh that has been made, the sw-420 vibration sensor is used to activate the GSM module and buzzer when someone steals a device that is already installed in the field. Programming using the Arduino IDE software. Based on the results of testing for 3 days, this rice pest control tool was able to eradicate 39 black ladybugs, rice stem borer, and stink bug.
\end{abstract}

Keywords-Rice Pests, Lamp DC, Microcontroller, Medium Voltage to Sting Rice Pests

Abstrak-Pada umumnya, pembasmian hama padi dilakukan dengan cara penyemprotan pestisida. Hal ini akan mengakibatkan tanah dan tanaman padi tercemar. Penelitian ini bertujuan untuk membuat alat pembasmi hama otomatis yang ramah lingkungan tanpa menggunakan pestisida. Penelitian ini juga membuat sistem pengaman alat dengan pemberitahuan suara buzzer dan pesan singkat di android. Metode pelaksanaan yang dilakukan agar berhasil membuat alat pembasmi hama tanaman padi otomatis menggunakan tegangan kejut listrik dimulai dari perancangan hardware kemudian pengumpulan data dan melakukan penelitian dengan menguji coba alat di sawah untuk melihat keefektifan alat. Pada perancangan ini, mikrokontroler Atmega 328 Arduino UNO digunakan sebagai pusat pengendali sistem, sensor LDR digunakan sebagai pengganti sakelar lampu DC dimalam hari untuk membuat hama mendekat sesuai dengan karakteristiknya yang tertarik dengan cahaya, kemudian tegangan kejut listrik akan aktif setiap 1 menit untuk menyengat hama yang menempel pada jaring kawat yang sudah dibuat, sensor getar sw-420 digunakan untuk mengaktifkan modul GSM dan buzzer ketika seseorang mencuri alat yang sudah terpasang di sawah. Pemrograman menggunakan software Arduino IDE. Berdasarkan hasil pengujian selama 3 hari, alat pembasmi hama padi ini dapat membasmi 39 hama kepik hitam, penggerek batang padi, dan walang sangit.

Kata kunci-Padi, Lampu DC, Mikrokontroler, Tegangan Menengah untuk Menyengat Hama Padi

\section{Pendahuluan}

Seiring meningkatnya kebutuhan hidup, perkembangan teknologi menjadi semakin pesat. Hamper semua peralatan yang dibuat oleh manusia cenderung semakin canggih, praktis, dan modern. Peralatan tersebut dapat membantu aktivitas manusia menjadi lebih mudah. Salah satunya seperti pembasmi hama yang dilakukan untuk mendapatkan hasil padi yang baik. Untuk mendapatkan hasil produksi yang baikdiharuskan melakukan perawatan yang rutin seperti membasmi hama yang akan merusaka tanaman padi.

Hasil panen padi akan terancam habis apabila serangan hama sering dating tiba-tiba. Untuk mengantisipasi penyebaran hama tanaman padi, petani melakukan penyemprotan dengan pestisida tetapi, cara seperti ini tidak efektif Karena pestisida memiliki efek racun dan akan mengakibatkan tanah dan tanaman padi menjadi tercemar, walaupun pestisida dapat membunuh hama dengan cepat. Penggunaan Pestisida yang intensif memang telah memberikan kontribusi terhadap peningkatan produksi pertanian, tetapi juga berdampak negatif, yaitu menimbulkan resisten dan resurjen beberapa jenis hama dan kandungan pestisida yang membahayakan kesehatan manusia [1]. Penelitian ini bertujuan untuk membuat alat pembasmi hama tanaman padi otomatis berbasis mikrokontroler yang ramah lingkungan tanpa menggunakan pestisida.

Fototropik positif dan tenaga yang dimiliki hama penggerek dewasa kuat untuk terbang dimalam hari. Penggerek batang mulai muncul ketika menjelang fajar sampai tengah malam [2]. Secara alami ngengat penggerek batang dan jenis hama padi lainnya tertarik dengan cahaya di malam hari [3]. Wereng merupakan hama penting yang harus dibasmi, karena berkembang biak dengan cara membentuk populasi yang besar dalam waktu singkat. Wereng juga merusak pada semua fase pertumbuhan tanaman [4]. 


\section{Wereng}

Wereng merupakan serangga kecil penghisap cairan tumbuhan.Wereng merusak batang padi yang masih muda dan membentuk populasi cukup besar dalam waktu yang singkat. Wereng cokelat dewasa sangat tertarik dengan cahaya yang sering disebut sifat fototaksis yang ada pada serangga umumnya. Dimana sifat fototaksis merupakan reaksi hewan terhadap cahaya dan serangga menyukai warna yang kontras. Karena itu hama jenis ini sangat penting untuk dibasmi[5].

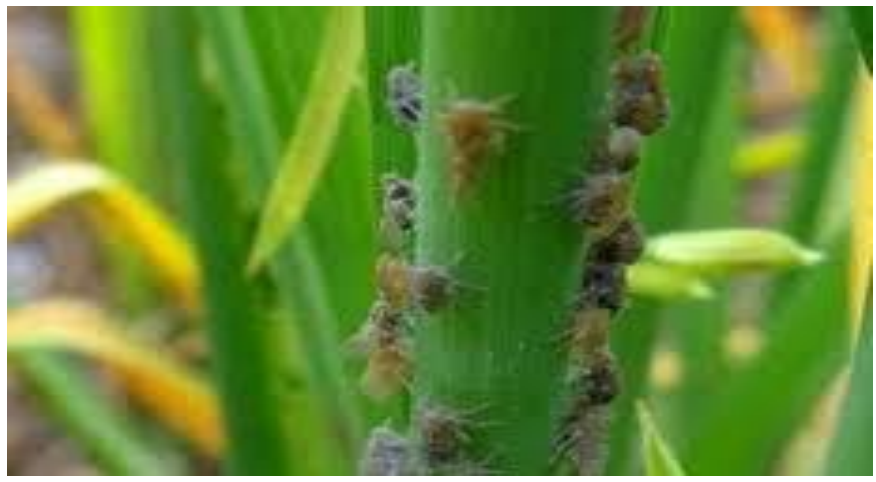

Gambar 1. Wereng

\section{Walang Sangit}

Walang sangit merupakan hama penting yang harus dibasmi karena mengganggu pertumbuhan padi. Walang sangit menyerang bulir padi yang masih matang susu dengan cara menghisap cairan pada bulir padi sehingga menyebabkan bulir tanaman menjadi kosong. Tangkai bunga pada tanaman dihisap oleh walang sangit sehingga tanaman tersebut kekurangan hara lalu menguning dan melemah. Hama ini mempertahankan dirinya dari musuh yang berada disekitarnya dengan cara mengeluarkan aroma yang menyengat hidung[6].

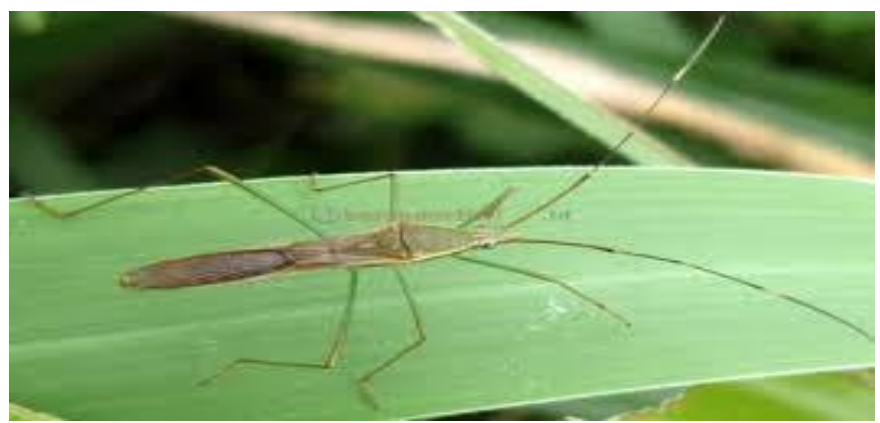

Gambar 2. Walang Sangit

\section{Kepik Hitam}

Kepik hitam menyerang tanaman padi dengan cara menusukkan siletnya kedalam bulir padi dan menghisap cairan gabah, sehingga mengakibatkan bulir padi tersebut menjadi cokelat. Gabah yang digiling menjadi beras banyak yang hancur dan berwarna kehitaman[7].

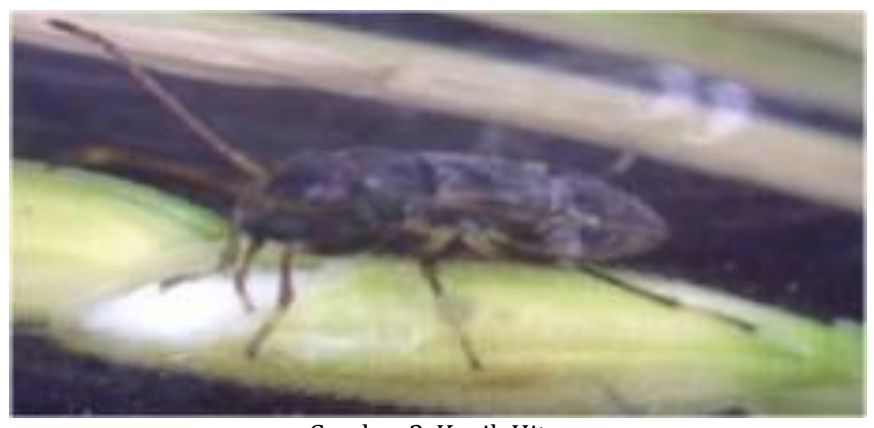

Gambar 3. Kepik Hitam

\section{Penggerek Batang Padi}

Penggerek batang padi menyerang tanaman padi mulai dari fase vegetative (masa pembungaan) yang akan merusak system pembuluh tanaman yang terdapat pada batang padi sampai fase generative (masa pembentukan malai) yang akan menyebabkan bulir padi menjadi kosong akibat proses pengisian bijinya tidak berjalan sempurna[8].

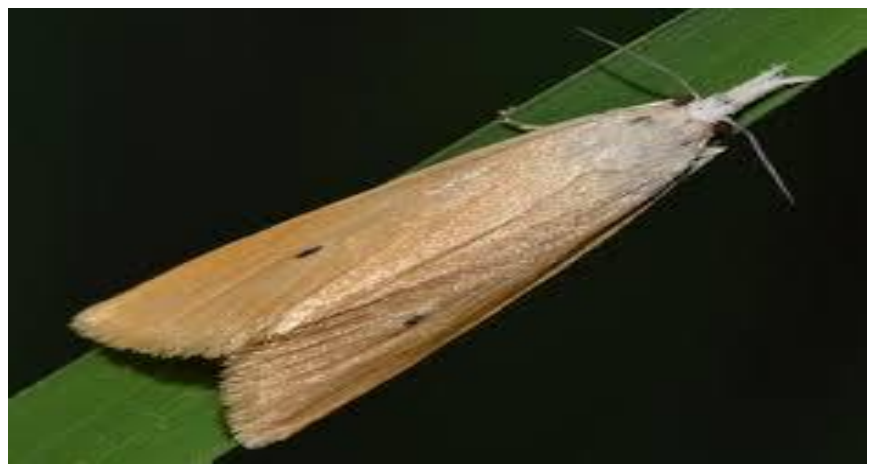

Gambar 4. Penggerek Batang Padi

\section{Mikrokontroler Arduino Uno}

Arduino Uno merupakan mikroprosesor jenis Atmel AVR yang memiliki beberapa pin diantaranya pin 0-13, fungsinya untuk isyarat digital yang hanya bernilai 1 dan 0 . Pin A0-A5 fungsinya untuk isyarat analog. Arduino dilengkapi dengan osilator $16 \mathrm{MHz}$ dan regulator 5 volt serta dilengkapi static random-accessmemory (SRAM) berukuran $2 \mathrm{~kb}$ untuk menyimpan data, flash memory berukuran $32 \mathrm{~kb}$, dan erasable programmable read-only memory (EEPROM) untuk menyimpan program[9].

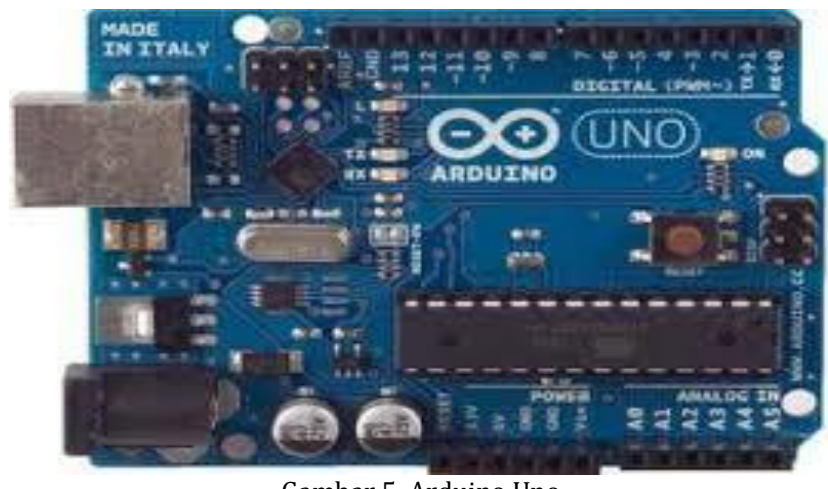

Gambar 5. Arduino Uno

\section{Sensor LDR (Light Dependent Resistor)}

Sensor LDR merupakan jenis resistor yang mempunyai nilai resistansi berubah ubah tergantung pada intensitas cahaya yang 
diterimanya.Sensor ini berfungsi sebagai pengganti sakelar lampu DC.Prinsip kerja sensor LDR yaitu, semakin tinggi intensitas cahay yang diterima sensor LDR (kondisi terang) maka, semakin kecil nilai tahanannya.Begitupun sebaliknya, semakin rendah intensitas cahaya yang diterima sensor LDR (kondisi gelap) maka, semakin besar nilai hambatannya[10].

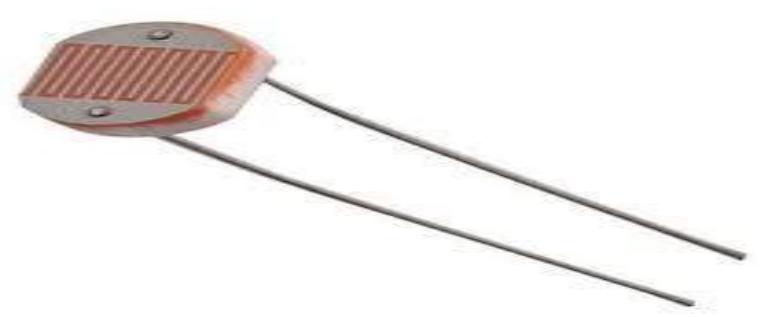

Gambar 6. Sensor LDR

\section{Sensor Vibration SW-420}

Sensor ini biasanya digunakan sebagai pendeteksi getaran. Spesifikasi modul sensor vibration SW-420 yaitu, dapat bekerja dengan tegangan 3,3V - 5V, dan memakai comparator LM393, Sensor getar ini akan aktif ketika muncul getaran karena ada seseorang yang mencuri alat yang sudah terpasang di sawah.

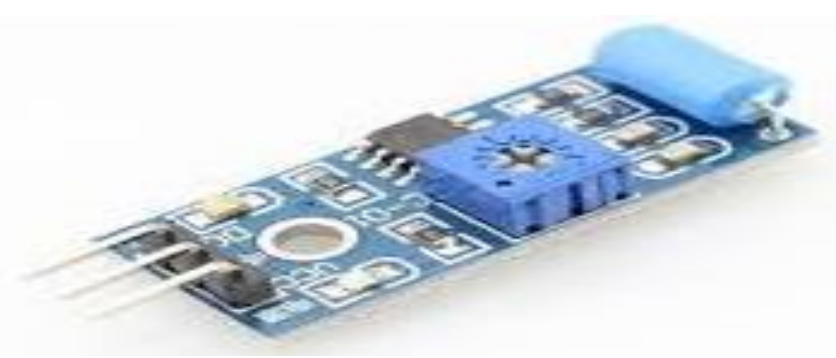

Gambar 7. Sensor Vibration SW-420

\section{Modul SIM 800L V.2}

Modul ini menggunakan power supply 5Vdc. Modul SIM digunakan untuk mengirimkan pemberitahuan ada maling berupa pesan singkat ke handphone pemilik alat. Modul ini menggunakan perintah AT Command untuk mengoperasikannya. Pada saat diberikan simcard pada modul ini, dimana kartu simcard telah aktif dan siap digunakan dengan indicator Network LED. Berikut adalah kondisi Network LED, yaitu kondisI pencarian jaringan (berkedip cepat) dan kondisi network registed (berkedip lambat)[11].
CHIP SIM800L

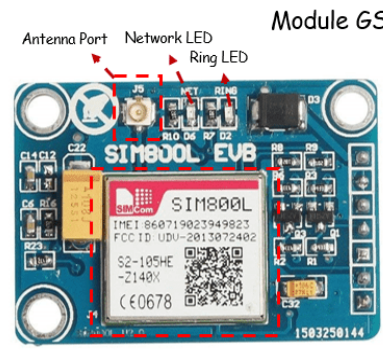

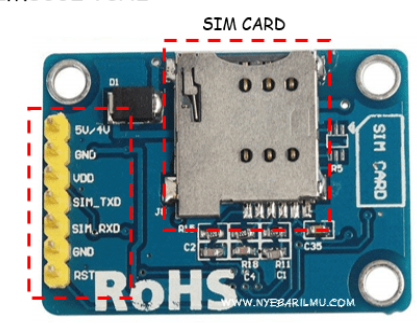

PIN INTERFACE
Gambar 8. Modul GSM SIM800LV.2

\section{Buzzer}

Komponen yang dapat mengubah getaran listrik menjadi getaran suara disebut buzze. Dimana cara kerjanya yaitu, kumparan yang terdapat pada diafragma akan dialiri arus sehingga berubah menjadi elektromagnet. Setiap gerakan kumparan yang ditariik keluar atau kedalam akan membuat diafragma bergerak bolak-balik sehingga udara menjadi bergetar yang kemudian akan mengeluarkan suara. Buzzer ini berfungsi sebagai pemberitahuan dalam bentuk suara jika ada orang yang mencuri alat.

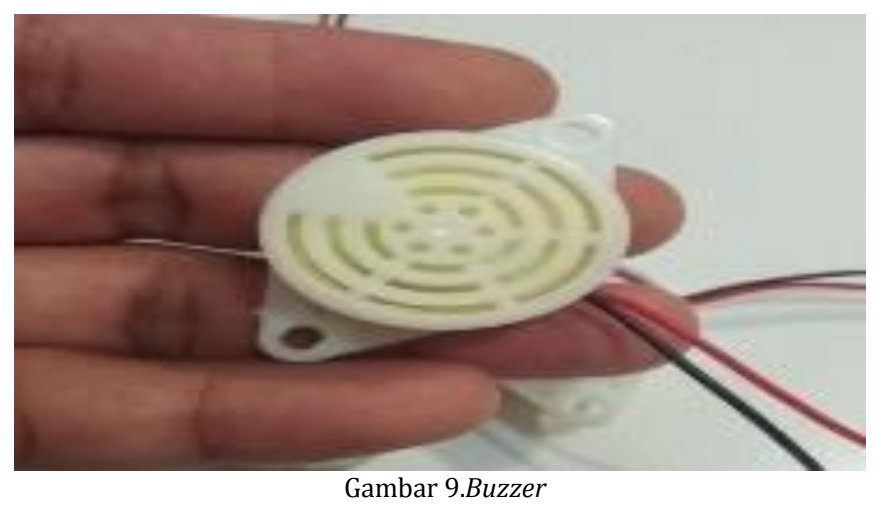

\section{LCD (Liquid Crystal Display)}

Dapat menampilkan pemberitahuan yang kita inginkan melalui tulisan karena banyak titik cahaya yang terdiri dari kristal cair. LCD yang biasa digunakan yaitu LCD yang memiliki karakter $16 \times 2$.

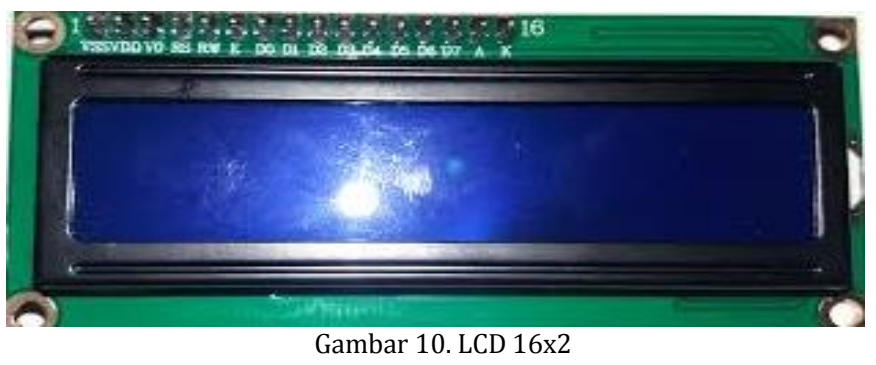

\section{Tegangan Menengah}

menengah dibuat dengan cara membuat trafo sederhana sendiri. Sebuah trasformator yang sederhana pada dasarnya terdiri dari 2 lilitan atau kumparan kawat yang terisolasi yaitu kumparan primer dan sekunder. Biasanya kumparan kawat terisolasi ini dililitkan pada sebuah besi yang dinamakan inti besi (core).

Semakin besar arus listriknya, semakin besar pula medan magnetnya. Fluktuasi medan magnet yang terjadi disekitar kumparan primer akan menginduksi GGL dalam kumparan sekunder. Dengan demikian, terjadilah pengubahan taraf tegangan listrik, baik dari tegangan rendah menjadi tegangan yang lebih tinggi maupun sebaliknya. Sekunder transformtor akan menghasilkan output tegangan yang lebih tinggi, tergantung pada jumlah lilitan kumparan sekunder transformator. Selain itu, rangkaian tegangan menengah ini menggunakan komponen seperti transistor BD139, IRF Z44N, dan resistor $150 \mathrm{ohm}$. 


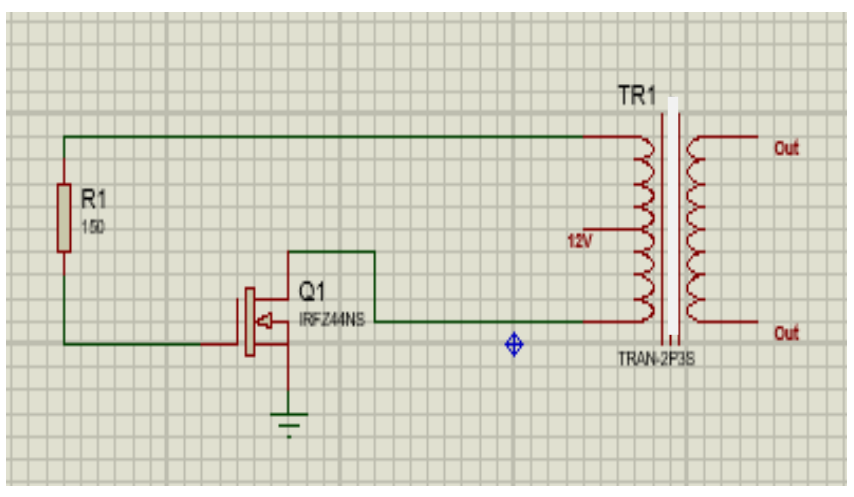

Gambar 11. Rangkaian Tegangan Menengah

\section{Stepdown DC}

Modul Stepdown atau penurun tegangan DC LM596 adalah modul yang memiliki IC LM2596 sebagai komponen utamanya. IC LM2596 merupakan sirkuit terpadu yang berfungsi sebagai Step-Down DC converter dengan current rating 3A. Terdapat beberapa varian dari IC seri ini yaitu versi adjustable yang tegangan keluarannya dapat diatur dan versi fixed voltage output yang tegangan keluarannya sudah tetap/fixed. Modul stepdown ini dapat membantu menurunkan tegangan ke tegangan yang lebih rendah. Berikut adalah spesifikasi umum dari modul stepdown DC LM2596 yaitu, Input voltage DC 3V-40V, Output voltage DC $1,5 \mathrm{~V}-35 \mathrm{~V}$, Arus maksimum $3 \mathrm{~A}$, dan ukuran board $42 \mathrm{~mm} \times 20 \mathrm{~mm} \times 14 \mathrm{~mm}$.

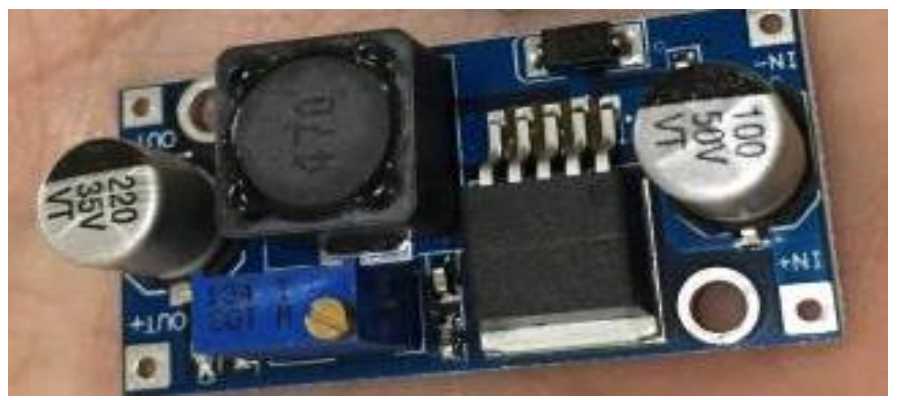

Gambar 12. Dc Stepdown

\section{Flowchart}

Flowchart merupakan suatu metode untuk menggambarkan aliran proses suatu operasi. Flowchart dibuat untuk menggambarkan suatu tahapan penyelesaian masalah secara sederhana, terurai, rapi dan jelas dengan menggunakan simbolsimbol standar yang ada.Membuat flowchart perlu memperhatikan penggunaan simbol yang tepat. Berikut adalah simbol flowchart antara lain sebagai berikut.
Tabel 1.Simbol-Simbol Standar dalam flowchart.

\begin{tabular}{|c|c|c|}
\hline Bagan & Nama & Fungsi \\
\hline & Terminator & Awal atau akhir program \\
\hline & Flow & Arah aliran program \\
\hline & Preparation & $\begin{array}{l}\text { Inisialisasi/pemberian nilai } \\
\text { awal }\end{array}$ \\
\hline & Process & Proses/pengolahan data \\
\hline & $\begin{array}{c}\text { Input/output } \\
\text { data }\end{array}$ & Input/output data \\
\hline & Sub program & Sub program \\
\hline & Decision & Seleksi atau kondisi \\
\hline & $\begin{array}{l}\text { On page } \\
\text { connector }\end{array}$ & $\begin{array}{l}\text { Penghubung bagian-bagian } \\
\text { flowchart pada halaman }\end{array}$ \\
\hline & $\begin{array}{l}\text { Off page } \\
\text { connector }\end{array}$ & $\begin{array}{l}\text { Penghubung bagian-bagian } \\
\text { flowchart pada halaman }\end{array}$ \\
\hline & Comment & $\begin{array}{l}\text { Tempat komentar tentang } \\
\text { suatu proses }\end{array}$ \\
\hline
\end{tabular}

\section{BLOK DIAGRAM}

Suatu pernyataan gambar yang ringkas dari gabungan sebab akibat antara masukan dan keluuaran system, dimana fungsinya untuk memudahkan dalam proses perancangan alat, perancangan mekanik serta memudahkan dalam proses analisa. Berikut adalah gambar blok diagram system alat.

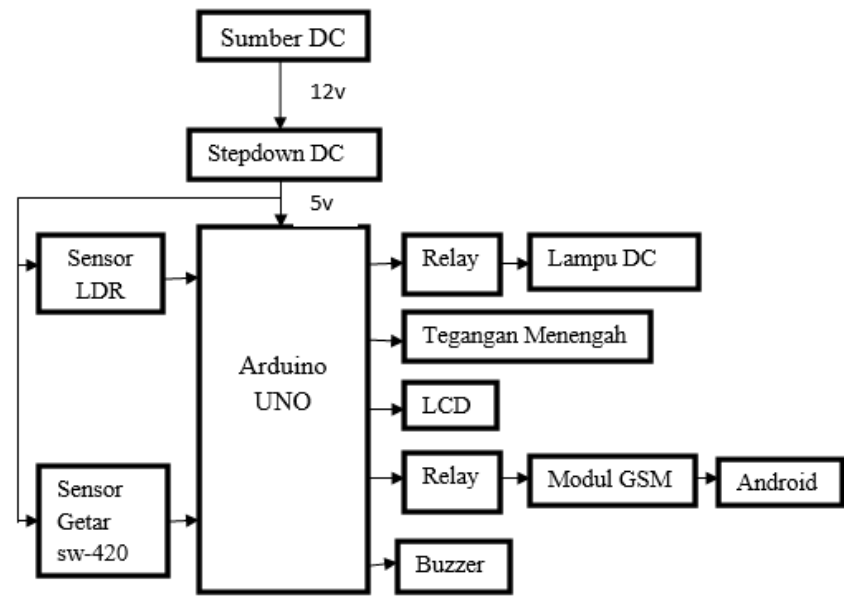

Gambar 13. Blok Diagram

Pada rangkaian ini penulis menggunakan sumber DC $12 \mathrm{~V}$ kemudian diturunkan menjadi $5 \mathrm{~V}$ dengan menggunakan modul Stepdown DC. Arduino Uno merupakan bagian yang berfungsi untuk memproses input yang dimasukkan dan menghasilkan output berupa aktifasi pada lampu DC, tegangan menengah, 
modul GSM, buzzer, dan LCD. Sensor LDR digunakan sebagai pengganti sakelar lampu DC.Sensor getar sw-420 digunakan unuk mengaktifkaan modul GSM dan buzzer. Lampu DC digunakan sebagai faktor yang membuat hama mendekat pada malam hari. Tegangan menengah pada kawat elektrik digunakan untuk membasmi hama. Modul GSM berfungsi sebagai media yang mengirimkan pemberitahuan berupa pesan singkat ke android dan buzzer berfungsi sebagai media yang mengeluarkan bunyi sebagai penanda ada seseorang yang mencuri alat yang terpasang di sawah.

Sistem pada alat ini bekerja secara otomatis, dimana sistemnya dikendalikan oleh mikrokontroler ATMega328 Arduino Uno dan bahasa c sebagai bahasa pemrogramannya. Prinsip kerja alat ini yaitu, lampu DC akan ON ketika malam hari yang akan dijadikan faktor hama mendekat. Tegangan kejut akan aktif setiap 1 menit untuk menyengat hama yang menempel pada jaring kawat. Ketika seseorang mencuri alat yang terpasang disawah, sensor getar sw-420 akan mengaktifkan modul SIM dan buzzer. Modul SIM yang akan mengirimkan pemberitahuan berupa pesan singkat ke android dan buzzer akan mengeluarkan pemberitahuan berupa suara.

\section{Perancangan Perangkas Keras}

Ini bertujuan untuk mengetahui komponen elektronika apa saja yang digunakan pada perancangan alat. Berikut adalah komponen yang digunakan yaitu,

1. Accumulator

2. Dc Stepdown

3. Mikrokontroler Arduino Uno

4. Sensor LDR

5. Sensor Vibration SW-420

6. Rangkaian Tegangan Menengah

7. Lampu Dc

8. LCD

9. Buzzer

10. Modul SIM 800L V.2

11. Relay $5 \mathrm{~V}$

12. Handphone

Mekanik perancangan alat dibuat sesuai dengan gambar dibawah ini.

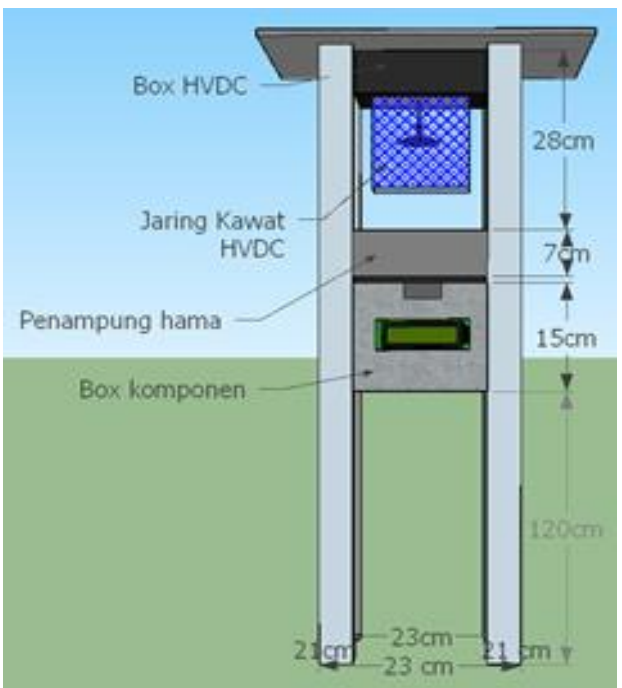

Gambar 14. Bentuk Alat

\section{Flowchart}

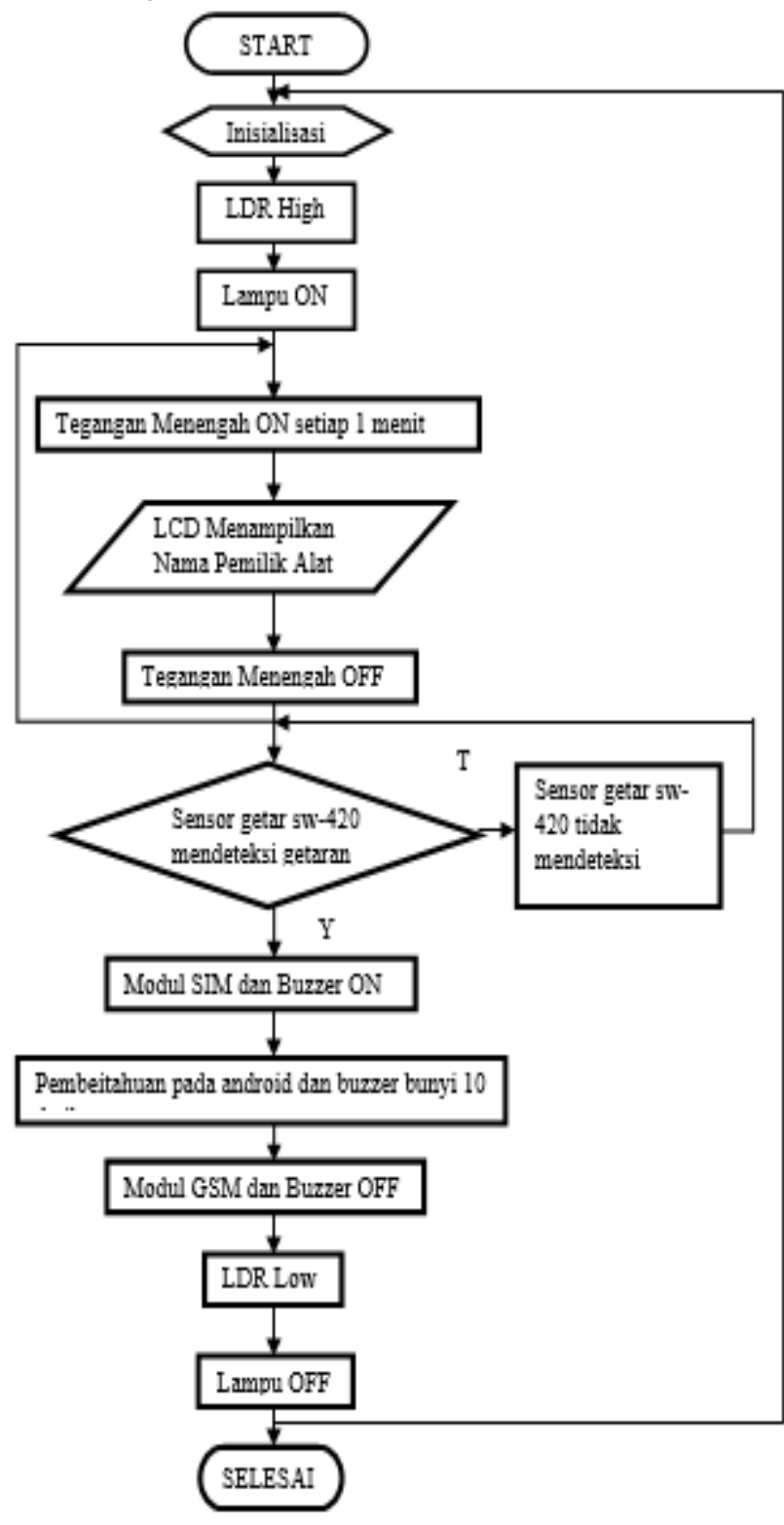

Gambar 15.Flowchart

\section{HASIL DAN PEMBAHASAN}

Untuk mengetahui sejauh mana alat yang telah dibuat dapat bekerja, apakah bekerja dengan baik atau tidak, maka diperlukan pengujian. Adapun pengujian yang dilakukan yaitu, pengujian Hardware seperti Arduino Uno, Sensor LDR, Sensor Vibration SW-420, Modul GSM SIM800L V.2, Buzzer, Relay 5V dan Pengujian alat pembasmi hama secara keseluruhan.

\section{Pengujian Hardware}

Pengujian hardware dilakukan untuk mengetahui prinsip kerja dan hasil kinerja pada masing-masing blok rangkaian yang telah dirancang agar didapatkan kinerja yang sesuai dengan yang diharapkan.Berikut adalah gambar mekanik alat. 


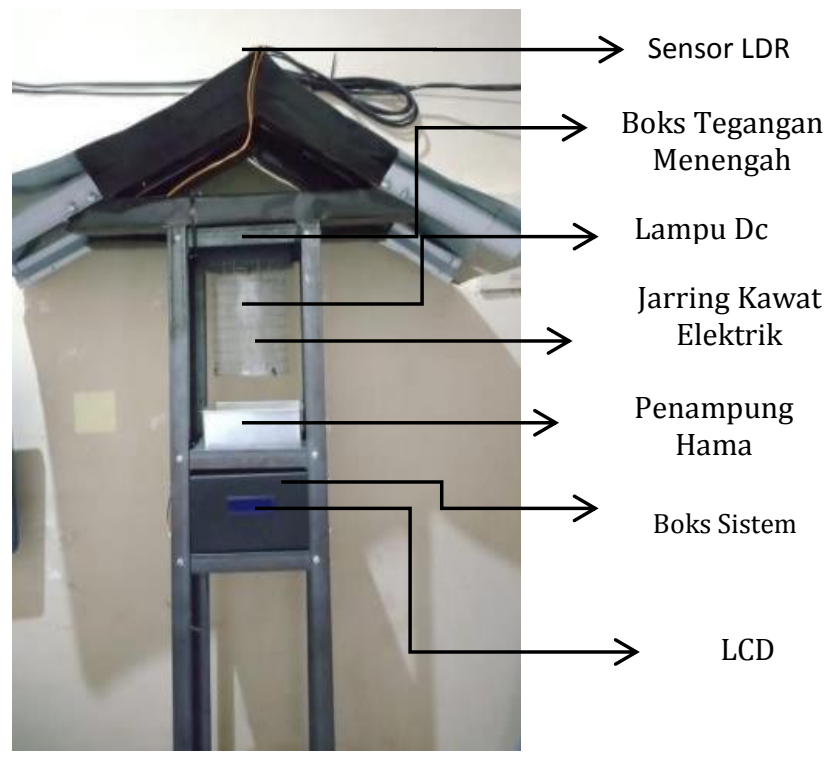

Gambar 16. Mekanik Alat

Berikut adalah tabel pengujian hardware dapat dilihat dibawah ini.

Tabel 2. Hasil Pengujian Hardware

\begin{tabular}{|c|c|c|}
\hline \multirow{2}{*}{ Komponen } & \multicolumn{2}{|c|}{ Tegangan Output } \\
\cline { 2 - 3 } & Low (0) & High (1) \\
\hline Arduino Uno & $0,03 \mathrm{~V}$ & $4,7 \mathrm{~V}$ \\
\hline Sensor LDR & $0,02 \mathrm{~V}$ & $4,8 \mathrm{~V}$ \\
\hline Sensor Vibration SW-420 & $0,17 \mathrm{~V}$ & $4,92 \mathrm{~V}$ \\
\hline Modul GSM SIM 800l V.2 & $0,01 \mathrm{~V}$ & $4,92 \mathrm{~V}$ \\
\hline Buzzer & $0,01 \mathrm{~V}$ & $4,65 \mathrm{~V}$ \\
\hline Relay 5V & $0,02 \mathrm{~V}$ & $4,94 \mathrm{~V}$ \\
\hline
\end{tabular}

\section{Pengujian Arduino Uno}

Pengujian Mikrokontroler Arduino UNO bertujuan untuk mengetahui besar tegangan keluaran yang dihasilkan.Mikrokontroler bekerja pada dua kondisi logika yaitu kondisi low (0) dan high (1). Pada saat kondisi logika low (0) tegangan yang terbaca pada pengukuran didapatkan tegangan sebesar $0.03 \mathrm{Vdc}$ yang berarti sistem masih dalam batas toleransi. Sedangkan pada kondisi logika high (1), tegangan yang terbaca pada pengukuran didapatkan tegangan sebesar 4,73 Vdc yang berarti sistem masih dalam batas ideal karena masih berada dalam range tegangan kerja.

\section{Pengujian Sensor LDR}

Pengujian pada sensor LDR dilakukan untuk mengetahui apakah sensor bekerja dengan baik atau tidak.Sensor LDR pada tugas akhir ini digunakan sebagai pensakelaran lampu di malam hari.Pada tabel2.dapat dikatakan bahwa sensor LDR telah bekerja dengan baik. Hasil pengukuran tegangan ketika sensor LDR aktif sebesar 4,8 volt, tidak beda jauh dari tegangan yang seharusnya 5 volt.

\section{Pengujian Sensor VibrationSW-420}

Pengujian pada sensor vibration SW-420 dilakukan untuk mengetahui apakah sensor bekerja dengan baik. Sensor vibrationSW-420 digunakan untuk sistem pengaman alat yang akan mengaktifkan modul SIM.

\section{Pengujian Modul SIM 800L V.2}

Pengujian Modul GSM SIM 800L bertujuan untuk mengetahui apakah tegangan pada Modul GSM bisa bekerja dengan baik atau tidak sesuai dengan datasheet yang ada. Pengujian dilakukan dengan cara menghubungkan VCC GSM dengan positif sumber dan menghubungkan ground GSM dengan negatif sumber. Berdasarkan hasil pengujian diatas bahwa tegangan sumber yangdiberikan 5 volt hanya menghasilkan tegangan keluaran GSM sebesar 4,92 volt. Artinya, tegangan ini masih bisa digunakan karena masih bekerja pada tegangan yang di perbolehkan. Tegangan yang dapat bekerja pada GSM SIM800L yaitu antara $3.1 \mathrm{~V}$ sampai 5 V.Modul GSM akan mengirimkan pesan ke handphone pemilik alat jika ada orang yang ingin mencuri alat. Berikut pemberitahuan SMS ketika ada yang mencuri alat.

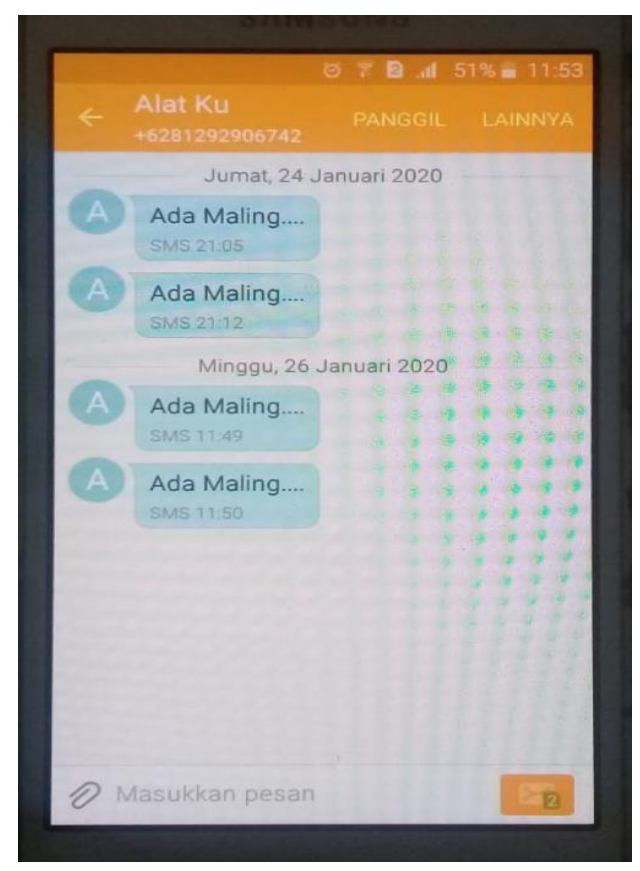

Gambar 17.SMS Pemberitahuan Maling di Handphone

\section{Pengujian Buzzer}

Pengujian ini dilakukan untuk mengetahui apakah buzzer dapat bekerja dengan baik. Pengujian pada buzzer dilakukan dengan memberikan tegangan sumber sebesar $5 \mathrm{Vdc}$ pada kaki positif $(+)$ dan logika low pada kaki negarif $(-)$ yang terhuung pada arduino uno.

\section{Pengujian Relay}

Pada tugas akhir ini menggunakan 2 buah relay. Pengujian rangkaianrelay bertujuan untuk memastikan rangkaian dapat bekerja dengan baik. Masukan pada relay didapat dari catu daya 
5 Vdc, hasil dari pengukuran yang didapatkan sebesar 4,94 Volt. Berdasarkan dari pengukuran dan pengujian, maka rangkaian relay telah bekerja dengan baik sesuai dengan batas toleransi.

Berdasarkan pengujian yang telah dilakukan, alat dapat berfungsi dengan baik. Tegangan output yang terukur pada setiap komponen masih bekerja padategangan yang diperbolehkan.

\section{Pengujian Alat Pembasmi Hama Secara Keseluruhan}

Pengujian ini dilakukan untuk mengetahui apakah sistem alat pembasmi hama padi bekerja dengan baik atau tidak. Pengujian alat di lakukan pada lokasi persawahan guna mengetahui aktivitas serangga pada malam hari yang dapat mempengaruhi tanaman padi.Alat ini di uji mulai dari pukul 19.00 WIB sampai dengan pukul 21.00 WIB. Adapun yang akan diamati dan dihitung dari pengujian ini adalah jumlah dan jenis serangga yang terbasmi.

Tabel 3. Hasil Pengujian alat pembasmi hama di sawah

\begin{tabular}{|c|l|c|}
\hline Hari & \multicolumn{1}{|c|}{ Jenis Serangga } & Jumlah \\
\hline 1 & $\begin{array}{l}\text { Kepik hitam dan penggerek batang } \\
\text { padi }\end{array}$ & 5 \\
\hline 2 & $\begin{array}{l}\text { Kepik hitam, walang sangit, dan } \\
\text { penggerek batang padi }\end{array}$ & 18 \\
\hline 3 & Kepik hitam & 16 \\
\hline
\end{tabular}

Berdasarkan hasil pengujian yang didapatkan, alat pembasmi hama tanaman padi otomatis dapat berfungsi dengan baik. Lampu DC dapat bekerja dengan baik ketika sensor LDR dapat membaca intensitas cahaya pada dua kondisi waktu (siang hari dan malam hari), Hama padi yang beraktifitas di malam hari mendekati lampu yang terang, tegangan menengah dapat membuat hama padi tersengat, dan sistem pengaman alat juga bekerja dengan baik. Hal ini ditandai dengan terkirimnya pesan maling ke handphone pemilik alat dan buzzer hidup ketika ada yang mencuri alat. Berikut adalah gambar Pengujian alat di sawah.
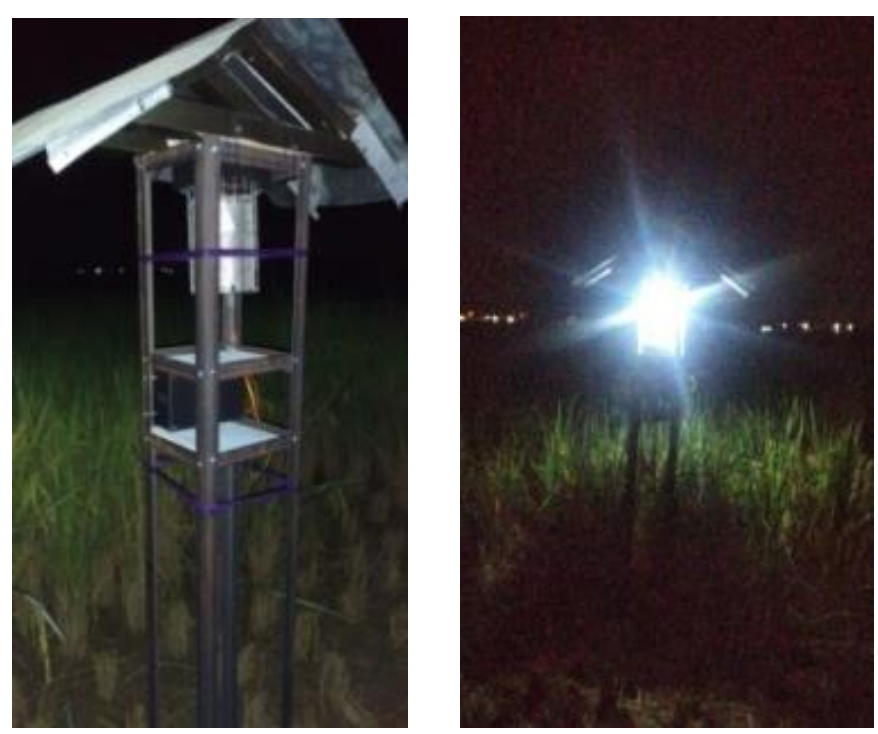

Gambar 18.AlatSaat Kondisi OFF

Gambar 19. AlatSaat Kondisi ON

\section{PENUTUP}

Berdasarkan hasil pengujian hardware dan software pada alat pembasmi hama tanaman padi berbasis mikrokontroler menggunkan tegangan kejut listrik maka dapat diperoleh kesimpulan seperti yang dijelaskan dibawah ini :

Telah berhasil di desain dan dibuat alat pembasmi hama tanaman padiotomatis berbasis mikrokontroler dengan kejutan listrik beserta sistem pengaman alat yang listriknya bersumber dari accu 12 volt. Pembuatan hardware menggunakan besi siku $3 \times 3$ sebagai tiangnya dengan tinggi 1,7 meter, karena memperkirakan tinggi padi. Alat ini memiliki 2 boks sistem untuk rangkaian menengah dan sistem alat. Kemudian lampu DC dan jaring kawat elektrik untuk membasmi hama.Program yang dibuat dengan menggunakan IDE arduino dapat diaplikasikan untuk alat pembasmi hama otomatis.Berdasarkan pengujian yang telah dilakukan, alat dapat berfungsi dengan baik yaitu, Lampu DC dapat bekerja dengan baik ketika sensor LDR dapat membaca intensitas cahaya pada dua kondisi waktu (siang hari dan malam hari), tegangan menengah dapat membuat hama padi tersengat, dan sistem pengaman alat dapat bekerja dengan baik. Hal ini ditandai dengan terkirimnya pesan maling ke handpone petani dan buzzer hidup ketika ada yang mencuri alat.Alat pembasmi hamatanaman padi otomatis ini dapat beroperasi dengan baik saat diujikan langsung di sawah. Alat dihidupkan mulai dari pukul 19.00 sampai 21.00 WIB dan dapat membasmi hama tanaman padi seperti kepik hitam, walang sangit, dan penggerek batang dengan jumlah sebesar 39 hama selama 3 hari. Seranggayang paling banyak datang mendekati lampu yakni dari jam 19.00-20.00.

\section{REFERENSI} penyakit tanaman padi secara terpadu," Badan Penelitian dan Pengembangan Pertanian-Balitbangtan. pp. 441442, 2009.

B. Besar and P. Tanaman, "Hama Penggerek Batang Padi dan Teknologi Pengendalian," Iptek Tanam. Pangan, vol. 8, no. 1, pp. 1-14, 2015.

W. Alamsyah, O. Nurhilal, J. Y. Mindara, A. H. I. Saad, and S. Hidayat, "Alat Perangkap Hama Dengan Metode Cahaya," J. Ilmu Dan Inov. Fis., vol. 01, no. 01, pp. 37-44, 2017.

B. Se, I. Made, and J. Mejaya, "Wereng Cokelat sebagai Hama Global Bernilai Ekonomi Tinggi dan Strategi Pengendaliannya," Iptek Tanam. Pangan, vol. 9, no. 1, pp. 1-12, 2015.

S. Pinandita, "Rancang Bangun Alat Pengendali Hama Wereng Mekanik Menggunakan LED dan Alat Penyedot," Jnteti, vol. 03, no. 04, pp. 281-286, 2014.

"Bbpadi_2009_Itp_16.Pdf.".

R. M, "101 EFIKASI CENDAWAN ENTOMOPATOGEN Mucor sp. TERHADAP MORTALITAS HAMA KEPIK HITAM ( Paraeucosmetus pallicornis Dallas) Oleh: Rahayu M. 1) , Asniah 1) dan Farisna 1)," vol. 26, pp. 101-106, 2016.

M. Alaminyapada and T. Padi, "Erlinda Damayanti, Gatot Mudjiono, Sri Karindah," J. HPT, vol. 3, no. April, pp. 1824, 2015.

U. A. Dahlan and J. R. Selatan, "Pengembangan Perangkat Praktikum Penentuan Ketebalan Plastik Transparan
I. N. Widiarta and H. Suharto, "Pengendalian hama dan 
Berbasis Sensor LDR Berbantuan Arduino Uno."

[10] S. SUPATMI, "Pengaruh Sensor Ldr Terhadap Pengontrolan Lampu," Maj. IIm. UNIKOM, vol. 8, no. 2, pp. 175-180, 2010.

[11] R. Fadly and Ci. Dewi, "Pengembangan Sensor Ultrasoic Guna Pengukuran Pasang Surut Laut Secara Otomatis dan Real Time," vol. 23, no. 1, pp. 1-16, 2019.

\section{Biodata Penulis}

Devinta Ayu Siregar, lahir di Ngawi, 31 Oktober 1997. Menyelesaikan Program Studi Teknik Elektro Industri (DIV), Jurusan Teknik Elektro FT-UNP.

Hambali, lahir di Bukittinggi, 8 Mei 1962. Menyelesaikan S1 Pendidikan Teknik Elektro FPTK IKIP Padang tahun 1987.Kemudian mendapatkan gelar Magister Kesehatan yang diperoleh di UGM Yogyakarta tahun 2005. Sejak tahun 1987 sampai sekarang menjadi staf pengajar tetap di Jurusan Teknik ElektroFT-UNP. 